\title{
Early and Late Outcomes of Diabetic Patients Treated with Drug-Eluting Stents in the Safira Registry
}

\author{
Julio Flávio Meirelles Marchini ${ }^{1}$, Adnan Ali Salman², Salvador Andre Bavaresco Cristóvão, \\ Nadia de Mendonça Carnieto ${ }^{4}$, Maria Fernanda Zuliani Mauro ${ }^{5}$, Eduardo Erudilho ${ }^{6}$, Raphael Moura \\ Garcia $^{7}$, Fernanda Joslin Oliveira ${ }^{8}$, Gabriel Gonzalo Penaranda Elias ${ }^{9}$, Breno Abrahão Maués Soares ${ }^{10}$, \\ Antonio Carvalho Cunha ${ }^{11}$, J. Armando Mangione ${ }^{12}$
}

\begin{abstract}
Background: The percutaneous treatment of coronary artery disease has been revolutionized by the use of drug-eluting stents (DES). However, its use in the daily practice involves patients with more complex clinical and angiographic characteristics than those found in randomized trials. This registry was designed to characterize diabetic patients and their outcomes following DES implantation in our country. Methods: Prospective single-center registry enrolling consecutive patients after DES implantation. Clinical, angiographic and procedurerelated data, as well as early and long-term outcomes were recorded. The primary endpoint, including cardiac death, myocardial infarction or target lesion revascularization, was compared between diabetics and non-diabetics. Results: We evaluated 1,670 patients treated with DES from 2002 to 2012 with a follow-up of $3.2 \pm 2.5$ years. One third of the patients were diabetic and had lower event-free survival when compared to non-diabetic patients $(79.4 \%$ vs. $82.6 \% ; \mathrm{P}=0.015)$. The adjusted odds ratio, however, was $1.22(95 \% \mathrm{Cl}, 0.89-1.69)$ and was not significant. A significantly lower event-free survival was observed in the subgroup of patients receiving insulin, whereas it was similar for diabetic and nondiabetic patients in the subgroup not receiving insulin $(68.7 \%$ vs. $83.9 \%$ vs. $82.8 \%$, respectively; $\mathrm{P}<0.01)$. The adjusted odds ratio was $1.72(95 \% \mathrm{Cl}, 1.13-2.63)$ higher for diabetic patients receiving insulin when compared to the remaining patients.
\end{abstract}

\section{RESUMO}

\section{Resultados Iniciais e Tardios de Diabéticos Tratados com Stents Farmacológicos do Registro Safira}

Introdução: O tratamento percutâneo da doença arterial coronária foi revolucionado pelo uso dos stents farmacológicos (SF). No entanto, sua utilização na prática diária envolve pacientes com características clínicas e angiográficas mais complexas dos que aquelas encontradas em estudos randomizados. Este registro se propôs a caracterizar, em nosso meio, diabéticos e seus desfechos clínicos após implante de SF. Métodos: Registro unicêntrico, prospectivo, que arrolou pacientes consecutivos submetidos a implante de SF. Foram registrados dados clínicos, angiográficos e do procedimento, assim como os desfechos hospitalares e tardios. A avaliação do desfecho primário, composto por óbito cardíaco, infarto agudo do miocárdio ou revascularização da lesão-alvo, foi realizada comparando-se pacientes diabéticos e não diabéticos. Resultados: Avaliamos 1.670 pacientes tratados com SF no período de 2002 a 2012, com seguimento de 3,2 $\pm 2,5$ anos. Um terço dos pacientes era diabético e apresentou sobrevivência livre de eventos menor que os não diabéticos $(79,4 \%$ vs. $82,6 \% ; \mathrm{P}=0,02)$. A razão de risco ajustada, no entanto, foi de 1,22 (IC 95\%, 0,89-1,69) - não significativa. Ao analisar o subgrupo dos pacientes em uso de insulina, encontramos sobrevivência livre de eventos significativamente menor que a dos demais,

\footnotetext{
${ }^{1}$ Ph.D. Resident physician of the Interventional Cardiology Ariê Team of the Hospital Beneficência Portuguesa de São Paulo. São Paulo, SP, Brazil. ${ }^{2}$ Interventional cardiologist. Assistant of the Interventional Cardiology Ariê Team of the Hospital Beneficência Portuguesa de São Paulo. São Paulo, SP, Brazil.

${ }^{3}$ Interventional cardiologist. Assistant of the Interventional Cardiology Ariê Team of the Hospital Beneficência Portuguesa de São Paulo. São Paulo, SP, Brazil.

${ }^{4}$ Interventional cardiologist. Assistant of the Interventional Cardiology Ariê Team of the Hospital Beneficência Portuguesa de São Paulo. São Paulo, SP, Brazil.

${ }^{5}$ Ph.D. Interventional cardiologist. Assistant of the Interventional Cardiology Ariê Team of the Hospital Beneficência Portuguesa de São Paulo. São Paulo, SP, Brazil.

${ }^{6}$ Interventional cardiologist. Assistant of the Interventional Cardiology Ariê Team of the Hospital Beneficência Portuguesa de São Paulo. São Paulo, SP, Brazil.

${ }^{7}$ Resident at the Interventional Cardiology Ariê Team of the Hospital
} Beneficência Portuguesa de São Paulo. São Paulo, SP, Brazil.
${ }^{8}$ Resident at the Interventional Cardiology Ariê Team of the Hospital
Beneficência Portuguesa de São Paulo. São Paulo, SP, Brazil.
${ }^{9}$ Resident at the Interventional Cardiology Ariê Team of the Hospital
Beneficência Portuguesa de São Paulo. São Paulo, SP, Brazil.
${ }^{10}$ Resident at the Interventional Cardiology Ariê Team of the Hospital
Beneficência Portuguesa de São Paulo. São Paulo, SP, Brazil.
${ }^{11}$ Resident at the Interventional Cardiology Ariê Team of the Hospital
Beneficência Portuguesa de São Paulo. São Paulo, SP, Brazil.
${ }^{12}$ Full professor. Director of the Interventional Cardiology Team Ariê of
the Hospital Beneficência Portuguesa de São Paulo. São Paulo, SP, Brazil.

Correspondence to: J. Armando Mangione. R. Maestro Cardim, 768, 19 subsolo, sala 73 - Bela Vista - São Paulo, SP, Brazil - CEP 01323-900 E-mail: mangi@terra.com.br

Received on: 6/25/2013 • Accepted on: 9/2/2013 
Conclusions: The use of DES is beneficial for all diabetic patients, especially those who do not receive insulin.

DESCRIPTORS: Coronary disease. Diabetes mellitus, type 2. Drug-eluting stents. Percutaneous coronary intervention.

$\mathrm{T}$ he technology that enabled the coating of metallic stents with drugs has revolutionized interventional cardiology. Drug-eluting stents (DES) have the ability to reduce neointimal hyperplasia, decreasing the coronary restenosis and the need for subsequent revascularizations. ${ }^{1}$ With such benefits, these new devices have expanded the indications for percutaneous treatment for lesions and in more complex patients. ${ }^{2}$

However, despite their routine use, there are still doubts about the results of DES in the population that usually presents clinical and angiographic criteria not included in randomized clinical trials. Another important aspect to note is the lack of data from the Brazilian population, whose own cultural and social characteristics influence the adherence to treatment, besides the fact that its genetic composition differs from populations assessed in the large registries of the United States and Europe. ${ }^{3-6}$

The aim of the present study was to evaluate the initial and late events of a non-selected cohort of patients undergoing DES implantation, comparing diabetic and non-diabetic patients.

\section{METHODS}

This was a single-center prospective trial of consecutive patients with coronary artery disease treated with at least one DES from July 2002 to August 2012 in the Complexo Hospitalar, Real e Benemérita Sociedade Portuguesa de Beneficência, Hospitais São Joaquim e São José, and in the Interventionist Cardiology Service Ariê, in the city of São Paulo, SP, Brazil. Patients were included in the study after explanation, reading, and signing of the informed consent. The protocol for this project was duly approved by the research ethics committee under number 778-12, as was the informed consent form.

\section{Inclusion and exclusion criteria}

Patients $\geq 18$ years old, with indication for CABG regardless of clinical or angiographic picture, and who could be treated with available DES, were included. Patients with contraindications to the use of antiplatelet medication indicated by the pharmacological protocol enquanto que os diabéticos que não estavam em uso de insulina mostraram comportamento semelhante ao dos não diabéticos $(68,7 \%$ vs. $83,9 \%$ vs. $82,8 \%$, respectivamente; $P$ $<0,01$ ). A razão de risco ajustada foi 1,72 (IC 95\%, 1,132,63) vez maior para os diabéticos em uso de insulina em comparação aos demais pacientes. Conclusões: O uso de SF traz benefícios para todos os diabéticos, especialmente para os que não utilizam insulina.

DESCRITORES: Doença das coronárias. Diabetes mellitus tipo 2. Stents farmacológicos. Intervenção coronária percutânea.

and those who refused to sign the informed consent were excluded.

\section{Procedure and antiplatelet therapy}

Percutaneous coronary interventions (PCIs) were performed according to the technique recommended by the guidelines. ${ }^{7}$ The choice of the stent was left to the surgeons' discretion.

The antiplatelet protocol consisted of a combination of two antiplatelet agents, acetylsalicylic acid (ASA) and a P2Y12 inhibitor. ASA was used at a loading dose of $200 \mathrm{mg}$ and $100 \mathrm{mg}$ for maintenance; clopidogrel was used at a loading dose of 300-600 mg and $75 \mathrm{mg}$ for maintenance. With the availability of ticagrelor and prasugrel, these drugs have been incorporated into clinical practice at loading doses of 60 and $180 \mathrm{mg}$, and maintenance at $90 \mathrm{mg}$ twice daily and $10 \mathrm{mg}$, respectively. The P2Y12 inhibitors have been recommended for a minimum period of one year. The use of glycoprotein IIb/IIla inhibitors was at the discretion of the surgeon.

\section{Definitions and primary outcome}

The clinical follow-up was performed by medical consultation or telephone contact at 30 days, six months, one year, and annually thereafter. Adverse events were reviewed using data from medical records and reports from other hospitals where the adverse event occurred.

The diagnosis of diabetes was defined, in accordance with current consensus, as a fasting glucose $\geq 126 \mathrm{mg} / \mathrm{dL}$, glycaemia $\geq 200 \mathrm{mg} / \mathrm{dL}$ two hours after ingestion of $75 \mathrm{~g}$ glucose (glucose tolerance test), random blood glucose $\geq$ $200 \mathrm{mg} / \mathrm{dL}$ accompanied by symptoms of hyperglycaemia. ${ }^{8}$ The patients were also classified according to whether or not they needed insulin treatment.

Deaths were considered of cardiac origin, unless a noncardiac cause could be unequivocally established. Acute myocardial infarction (AMI) was defined as an increase in creatine kinase fraction $\mathrm{MB}(\mathrm{CK}-\mathrm{MB})$ superior to three times the upper limit of normal, with or without the appearance of new $Q$ waves. ${ }^{9}$ Target vessel revascularization (TVR) was defined as the ischemia-guided 
revascularization of the vessel treated at the index $\mathrm{PCl}$, whether by new $\mathrm{PCl}$ or coronary artery bypass graft (CABG), in the presence of symptoms or ischemia during the noninvasive stratification. Angiographic success was defined as achieving a stenosis diameter $<20 \%$ and Thrombolysis in Myocardial Infarction (TIMI) 3 flow. Procedural success was considered as angiographic success free of occurrence of death, AMI, or urgent TVR. The definition of TIMI bleeding was used to classify possible bleeding. ${ }^{10}$

The primary outcome was considered as the occurrence of cardiovascular death, nonfatal AMI, or ischemia-driven TVR in the late phase.

\section{Statistical analysis}

Continuous variables were presented as means and standard deviations and were compared by Student's t-test. Categorical variables were described as frequency and percentage, and were compared by the chi-squared or Fisher's exact test, where appropriate. Cumulative event rates were estimated by the Kaplan-Meier method, and differences were compared by log-rank test. Patients were followed-up until the occurrence of an outcome, or censored in December 2012. Statistical significance was considered at a level of $5 \%(P \leq 0.05)$.

Multivariate predictors of outcomes were tested using the proportional hazards model of Cox when they showed significant effects in the univariate model $(P<0.15)$. The predictors included in the model were age, gender, body mass index, hypertension, smoking state, dyslipidaemia, diabetes mellitus, prior AMI, previous stroke, peripheral vascular disease, previous revascularization, chronic renal failure, ventricular dysfunction, extent of coronary artery disease, treated vessel, type of injury, segmental or calcified

TABLE 1

Clinical and angiographic characteristics

\begin{tabular}{|c|c|c|c|}
\hline & Diabetics $n=540$ & Non diabetics $n=1,130$ & $\mathbf{P}$ \\
\hline Age, years & $63.9 \pm 10.3$ & $63.0 \pm 11.7$ & 0.11 \\
\hline Female, n (\%) & $175(32.4)$ & $298(26.4)$ & 0.01 \\
\hline $\mathrm{BMI}, \mathrm{kg} / \mathrm{m}^{2}$ & $28.6 \pm 4.7$ & $27.0 \pm 4.3$ & $<0.01$ \\
\hline Hypertension, n (\%) & $476(88.2)$ & $853(75.5)$ & $<0.01$ \\
\hline Dyslipidaemia, n (\%) & $401(74.3)$ & $717(63.5)$ & $<0.01$ \\
\hline Current smoking, n (\%) & $73(13.5)$ & $204(18.1)$ & $<0.01$ \\
\hline Family history of CAD, n (\%) & $215(39.8)$ & $453(40.1)$ & 0.92 \\
\hline Prior AMI, n (\%) & $116(23.0)$ & $266(23.5)$ & 0.79 \\
\hline Prior stroke, n (\%) & $14(2.6)$ & $24(2.1)$ & 0.55 \\
\hline Previous $\mathrm{PCl}, \mathrm{n}(\%)$ & $91(16.9)$ & $190(16.8)$ & 0.98 \\
\hline Previous CABG, n (\%) & $89(16.5)$ & $166(14.7)$ & 0.34 \\
\hline Chronic renal failure, n (\%) & $60(11.1)$ & $80(7.1)$ & $<0.01$ \\
\hline Chronic lung disease, n (\%) & $4(0.7)$ & $17(1.5)$ & 0.19 \\
\hline Peripheral vascular disease, n (\%) & $24(4.4)$ & $23(2.0)$ & $<0.01$ \\
\hline Clinical picture, n (\%) & & & 0.38 \\
\hline Silent ischemia & $119(22.0)$ & $260(23.1)$ & \\
\hline Stable angina & $295(54.6)$ & $596(52.8)$ & \\
\hline Unstable angina, low/moderate risk & $46(8.5)$ & $127(11.3)$ & \\
\hline Unstable angina, high-risk/ NSTE-MI & $75(13.9)$ & $130(11.5)$ & \\
\hline STE-MI & $4(0.5)$ & $15(1.3)$ & \\
\hline Extent of CAD & & & 0.01 \\
\hline 1 & $178(33.0)$ & $469(41.5)$ & \\
\hline 2 & $181(33.6)$ & $383(33.9)$ & \\
\hline 3 & $180(33.3)$ & $277(24.5)$ & \\
\hline LV dysfunction, n (\%) & & & 0.25 \\
\hline Light & $130(60.2)$ & $263(62.6)$ & \\
\hline Moderate & $61(28.2)$ & $117(27.9)$ & \\
\hline Severe & $25(1.6)$ & $40(9.5)$ & \\
\hline
\end{tabular}

$\mathrm{BMI}=$ body mass index; $\mathrm{CAD}=$ coronary artery disease $; \mathrm{AMI}=$ acute myocardial infarction; $\mathrm{PCI}=$ percutaneous coronary intervention; NSTE-MI = myocardial infarction without ST-segment elevation; STE-MI = myocardial infarction with ST-segment elevation; LV = left ventricle. 
lesions, treatment for venous and arterial grafts, stenosis diameter pre- and post-procedure, implantation technique of direct stent, and stent type.

Left ventricular dysfunction was defined according to a four-point scale (normal, mild dysfunction, moderate dysfunction, or severe dysfunction). The results are presented as risk ratio (RR) and 95\% confidence interval $(95 \% \mathrm{Cl})$. The proportional hazards assumption was confirmed by testing Schoenfeld residuals; no violations were found.

All analyses were performed using Stata (StataCorp - Texas, USA), version 12.

TABLE 2

Angiographic and procedural characteristics

\begin{tabular}{|c|c|c|c|}
\hline & $\begin{array}{c}\text { Diabetics } \\
\mathbf{n}=\mathbf{5 4 0} \text { patients } / 894 \\
\text { injuries }\end{array}$ & $\begin{array}{c}\text { Non-diabetics } \\
\mathrm{n}=\mathbf{1 , 1 3 0} \text { patients } / 1,685 \\
\text { injuries }\end{array}$ & $\begin{array}{c}P \\
0.38\end{array}$ \\
\hline \multicolumn{4}{|l|}{ Injury type, n (\%) } \\
\hline A & $74(8.3)$ & 149 (8.9) & \\
\hline B1 & $256(28.6)$ & $470(27.9)$ & \\
\hline B2 & $217(24.3)$ & $426(25.3)$ & \\
\hline $\mathrm{C}$ & 347 (38.8) & 637 (37.9) & 0.71 \\
\hline \multicolumn{4}{|l|}{ Initial TIMI flow, n (\%) } \\
\hline 0 & $30(3.4)$ & $90(5.4)$ & \\
\hline 1 & $43(4.8)$ & $94(5.1)$ & \\
\hline 2 & $78(8.7)$ & $127(7.6)$ & \\
\hline 3 & 737 (82.4) & $1.369(81.5)$ & \\
\hline Treated arteries, n (\%) & & & 0.77 \\
\hline LMCA & $14(1.6)$ & $29(1.7)$ & 0.25 \\
\hline LAD & $378(42.3)$ & $752(44.6)$ & 0.28 \\
\hline $\mathrm{LCx}$ & $224(25.1)$ & $390(23.2)$ & 0.65 \\
\hline $\mathrm{RC}$ & $228(25.5)$ & $416(24.7)$ & 0.63 \\
\hline LITA graft, n (\%) & $4(0.5)$ & $10(0.6)$ & 0.14 \\
\hline SVB graft, n (\%) & $17(1.9)$ & $48(2.9)$ & \\
\hline Characteristics of injury, n (\%) & & & 0.13 \\
\hline Thrombus & $16(1.8)$ & $54(3.2)$ & 0.44 \\
\hline Calcification moderate/severe & $146(16.3)$ & $255(15.1)$ & 0.13 \\
\hline Bifurcation & $48(5.4)$ & $125(7.4)$ & 0.35 \\
\hline Ostial lesion & $30(3.4)$ & $74(6.6)$ & 0.13 \\
\hline Chronic occlusion & $34(3.8)$ & $95(8.4)$ & \\
\hline Stenosis diameter, \% & & & 0.13 \\
\hline Pre & $79.7 \pm 11.3$ & $81.0 \pm 10.8$ & 0.48 \\
\hline Post & $1.1 \pm 3.7$ & $1.0 \pm 5.1$ & 0.85 \\
\hline Lesion length, mm & $20.5 \pm 7.0$ & $20.3 \pm 6.9$ & 0.29 \\
\hline Direct stent, n (\%) & $265(49.1)$ & $845(50.1)$ & $<0.01$ \\
\hline Stents per patient & $1.7 \pm 0.8$ & $1.5 \pm 0.7$ & 0.28 \\
\hline \multicolumn{4}{|l|}{ Final TIMI flow, n (\%) } \\
\hline 0 & $2(0.2)$ & $4(0.2)$ & \\
\hline 1 & 0 & 0 & \\
\hline 2 & $9(1.0)$ & $10(0.6)$ & \\
\hline 3 & $882(98.7)$ & $1,669(99.2)$ & \\
\hline
\end{tabular}

$\mathrm{TIMI}=$ Thrombolys in Myocardial Infarction; LMCA = left main coronary artery; LA D = left anterior descendent artery; LCx = left circumflex artery; RC = right coronary artery; LITA = left internal thoracic artery; SVB = saphenous vein bridge. 


\section{RESULTS}

During the reporting period, 1,670 patients underwent $\mathrm{PCl}$ only by DES implantation. Clinical, angiographic, and procedural characteristics are shown in Tables 1 and 2, and in Figure 1. Of these patients, 540 (32.3\%) had diabetes mellitus; $70.2 \%$ were under treatment with oral hypoglycaemic agents and $29.8 \%$ with insulin.

\section{In-hospital outcomes}

Angiographic success was achieved in $98.2 \%$ and procedural success in $96.7 \%$ of patients. The in-hospital results are shown in Table 3.

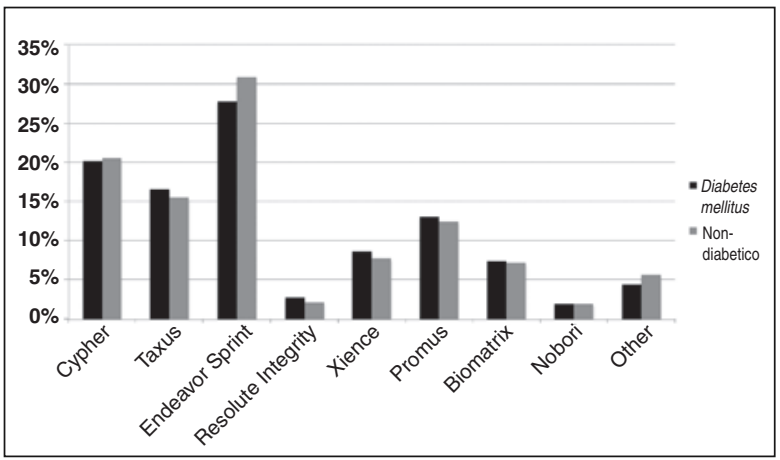

Figure 1 - Types of drug-eluting stents (DES) used in diabetic and non-diabetic patients. There was no significant difference in the use of any stent in diabetic and non-diabetic patients.

TABLE 3

Angiographic and clinical complications in in-hospital phase

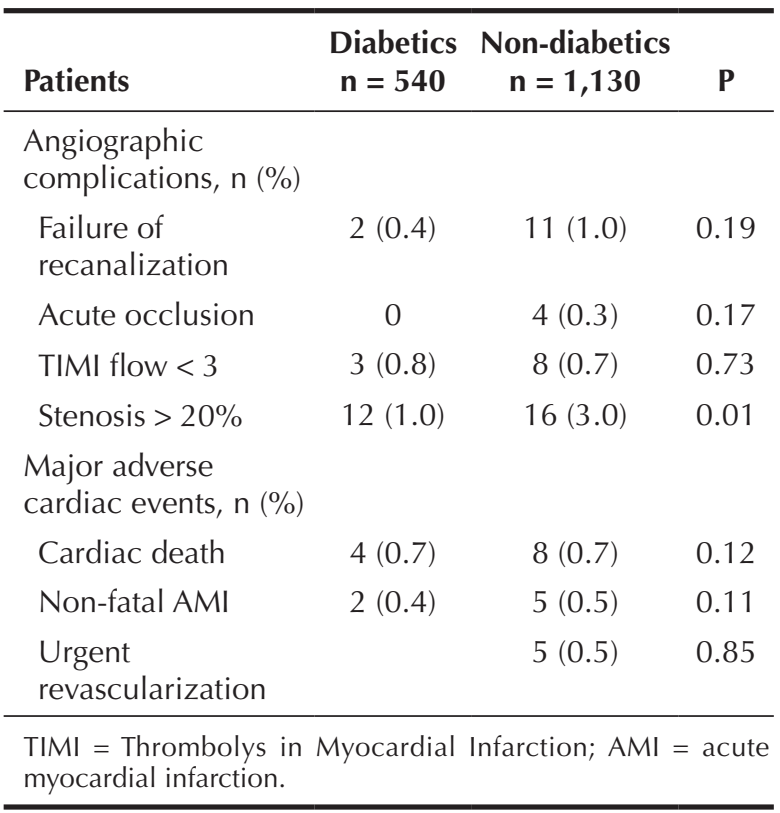

\section{Primary endpoint}

1,578 patients $(94.5 \%$ of those eligible) had clinical follow-up, with a mean time of $3.2 \pm 2.5$ years, and with a minimum of four months and a maximum of 10.3 years. The primary outcome occurred in 192 (13.9\%) patients; 130 deaths occurred (90 of cardiac causes; $5.7 \%), 32 \mathrm{AMI}(2.0 \%)$, and 70 TVR $(4.4 \%)$. The estimated survival free of the primary outcome was $81.6 \%$ in six years.

Diabetic patients had significantly lower survival free of events, compared to non-diabetic patients $(79.4 \%$ vs. $82.6 \%$; $P=0.02)$ (Figure 2). RR was $1.43(95 \% \mathrm{Cl}$, 1.07 to 1.92 ) for events in diabetic patients (Figure 3). However, after adjusting for confounder variables, the adjusted RR was $1.22(95 \% \mathrm{Cl}, 0.89$ to 1.69$)$, not statistically significant.

When comparing diabetics taking insulin, diabetics who were not taking insulin, and non-diabetics, the former showed survival free of events significantly lower than the other two groups, while diabetic patients who were not taking insulin showed similar behaviour to the non-diabetic ones $(68.7 \%$ vs. $83.9 \%$ vs. $82.8 \%$, respectively; $\mathrm{P}<0.01)$. RR was $2.34(95 \% \mathrm{Cl}, 1.62$ to 3.37) for diabetics using insulin, compared to the other patients (Figure 3). The adjusted RR was $1.72(95 \% \mathrm{Cl}$, 1.13 to 2.63$)$.

\section{DISCUSSION}

SAPPHIRE is the second published Brazilian registry evaluating the long-term follow-up of patients treated with DES. The DESIRE registry published its overall long-term results ${ }^{11}$ stratified by previous diabetes diagnosis. ${ }^{12}$ In the latter study, major adverse cardiac events occurred in $9.8 \%$ of diabetic patients and in $7 \%$ of non-diabetics, at a mean follow-up of $2.5 \pm 1.4$ years $(P=0.05)$. The observed differences in the incidence of events between the two registries are related to the different event definitions adopted, differences in clinical and angiographic profile of patients, and different follow-up times.

In the present study, diabetic patients who were not using insulin had late evolution similar to that of non-diabetic patients. The more favorable results of these less complex diabetic patients can be attributed to the use of DES. The SES-SMART trial, which compared the use of sirolimus-eluting stents versus bare-metal stents, showed lower restenosis in diabetic patients who were not using insulin (17\% vs. $63 \%$; $\mathrm{P}=0.01)$ - a benefit not observed in diabetic patients using insulin $(40 \%$ vs. $64 \% ; P=0.4) .^{13}$

The comparison of conventional stents and DES in 440 unselected patients found a reduction of cardiac events in both groups of diabetic patients (with and without use of insulin), which was higher in the second group (1.9 times and 3.3 times, respectively). ${ }^{14}$ 

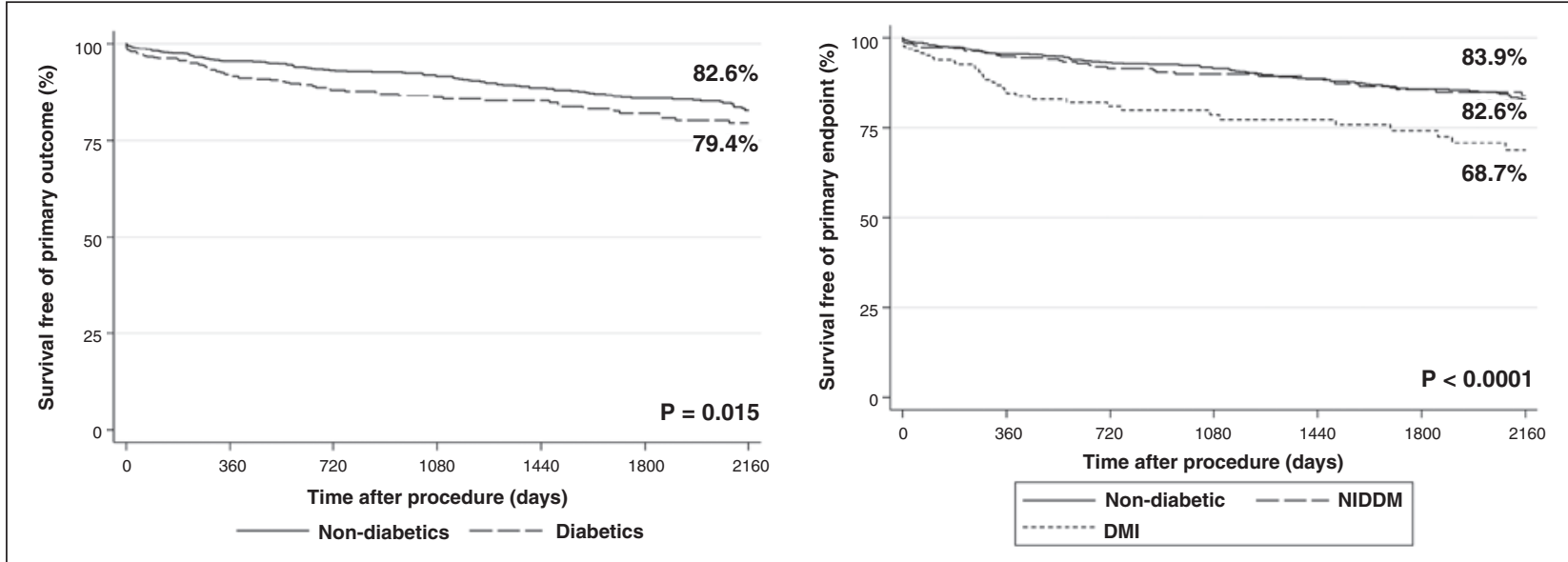

Figure 2 - Kaplan-Meier estimate for the primary endpoint. Left, results presented for diabetics and non-diabetics. Right, results presented for nondiabetics, diabetics not using insulin (NIDDM) and diabetics using insulin (DMI).

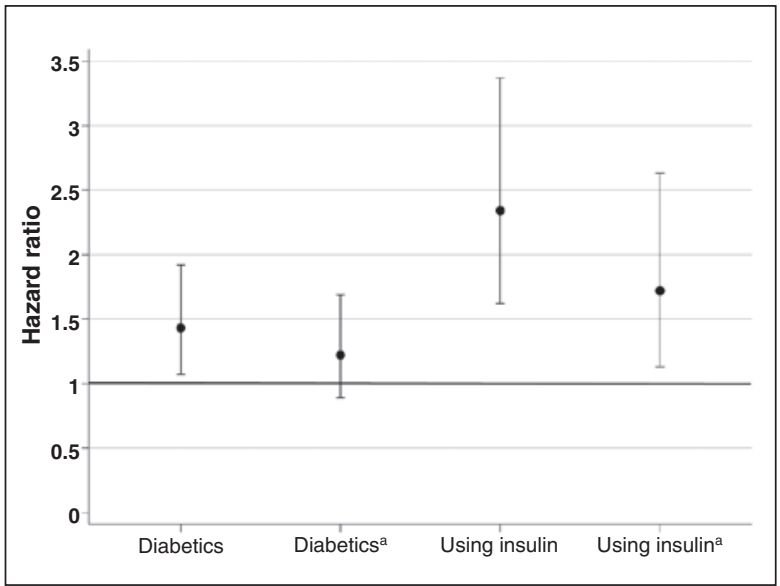

Figure 3 - Hazard ratio for the primary outcome for diabetic patients compared to non-diabetics, and for diabetics using insulin compared to the others.

In another study involving 231 patients, late loss and binary restenosis were higher in diabetics using insulin, compared to non-diabetics, whereas there was no difference between the group who were not taking insulin and the non-diabetic group. ${ }^{15}$ At one year of follow-up, a mean increase in target vessel failure and a trend towards higher mortality in the group taking insulin were observed, compared to non-diabetics ( $P$ $=0.06)-$ findings that were not present in the group that was not using insulin.

Diabetic patients have increased oxidative stress and inflammation, besides protein glycation; as a consequence, they develop more extensive atherosclerosis, coagulation disorders, and a greater number of vulnerable atherosclerotic plaques. Notably, patients using insulin also exhibit increased synthesis of plasminogen activation inhibitor-1 (PAI-1), which favors atherothrombotic events and inhibits the remodelling and proteolysis that occur after arterial injury, with consequent accumulation of extracellular matrix and neointimal hyperplasia, causing high rates of coronary restenosis. ${ }^{16}$

The SAPPHIRE registry shows rates of major adverse cardiac events consistent with other registries. ${ }^{12,17}$ According to the present results, it is concluded that the use of DES is of fundamental importance for the percutaneous treatment of coronary artery disease in diabetic patients, especially for those who do not use insulin, considering the reduction of risk of serious cardiac events to levels similar to those of non-diabetic patients.

\section{CONCLUSIONS}

In the present study, the use of DES was beneficial to all diabetics, especially those who did not use insulin.

\section{CONFLICTS OF INTEREST}

The authors declare no conflicts of interest.

\section{REFERENCES}

1. Garg S, Serruys PW. Coronary stents: current status. J Am Coll Cardiol. 2010;56(10 Suppl):S1-42.

2. Kirtane AJ, Gupta A, Iyengar S, Moses JW, Leon MB, Applegate R, et al. Safety and efficacy of drug-eluting and bare metal stents: comprehensive meta-analysis of randomized trials and observational studies. Circulation. 2009;119(25):3198-206.

3. Pavao R, Marin-Neto JA, Novaes GC, Pinto MR, Figueiredo GL, Lago IM, et al. Avaliação a médio prazo do controle de fatores de risco do doença cardiovascular em coorte prospectiva de pacientes de alto risco, tratados por intervençao coronária percutânea. Rev Bras Cardiol Invasiva. 2013;21(2):121-7. 
4. Giolo SR, Soler JM, Greenway SC, Almeida MA, Andrade M, Seidman JG, et al. Brazilian urban population genetic structure reveals a high degree of admixture. Eur J Hum Genet. 2012;20(1):111-6.

5. Tamburino C, Ciriminna S, Barbagallo R, Galassi AR, Ussia G, Capranzano $\mathrm{P}$, et al. Sicilian DES Registry: prospective inhospital and 9-month clinical and angiographic follow-up in selected high restenosis risk patients. J Cardiovasc Med (Hagerstown). 2008;9(2):161-8.

6. Williams DO, Abbott JD, Kip KE; DEScover Investigators. Outcomes of 6906 patients undergoing percutaneous coronary intervention in the era of drug-eluting stents: report of the DEScover Registry. Circulation. 2006;114(20):2154-62.

7. Mattos LA, Lemos Neto PA, Rassi Jr. A, Marin-Neto JA, Sousa AGMR, Devito FS, et al. Diretrizes da Sociedade Brasileira de Cardiologia - Intervenção Coronária Percutânea e Métodos Adjuntos Diagnósticos em Cardiologia Intervencionista (II Edição - 2008). Arq Bras Cardiol. 2008;91(6 Supl 1):1-58.

8. American Diabetes Association. Standards of medical care for patients with diabetes mellitus. Diabetes Care. 2002;25(1):213-29.

9. Thygesen K, Alpert JS, White HD, Jaffe AS, Apple FS, Galvani M, et al. Universal definition of myocardial infarction. Circulation. 2007;116(22):2634-53.

10. Mehran R, Rao SV, Bhatt DL, Gibson CM, Caixeta A, Eikelboom J, et al. Standardized bleeding definitions for cardiovascular clinical trials: a consensus report from the Bleeding Academic Research Consortium. Circulation. 2011;123(23):2736-47.

11. Costa JR Jr, Sousa A, Moreira AC, Costa RA, Cano M, Maldonado $G$, et al. Incidence and predictors of very late (>or $=4$ years) major cardiac adverse events in the DESIRE
(Drug-Eluting Stents in the Real World)-Late registry. JACC Cardiovasc Interv. 2010;3(1):12-8.

12. Moreira AC, Sousa AGMR, Costa Jr. JR, Costa RA, Maldonado GA, Cano $M N$, et al. Evolução tardia após intervenção coronária percutânea com stents farmacológicos em pacientes diabéticos do Registro DESIRE (Drug-Eluting Stents In the REal world). Rev Bras Cardiol Invasiva. 2008;16(2):185-92.

13. Ortolani $\mathrm{P}$, Ardissino D, Cavallini C, Bramucci E, Indolfi C, Aquilina $M$, et al. Effect of sirolimus-eluting stent in diabetic patients with small coronary arteries (a SES-SMART substudy). Am J Cardiol. 2005;96(10):1393-8.

14. Dominguez Franco AJ, Alonso Briales JH, Jimenez Navarro MF, Hernandez Garcia JM, Garcia Pinilla JM, Perez Caravante M et al. Clinical impact of drug-eluting stents in an unselected population of diabetic patients. Clin Cardiol. 2008;31(4):16571

15. Berenguer A, Mainar V, Bordes P, Valencia J, Gomez S. Efficacy of sirolimus-eluting stents in diabetics with complex coronary lesions. Rev Esp Cardiol. 2006;59(2):117-24.

16. Aronson D, Johnstone MT. Coronary artery disease in diabetes. In: Johnstone MT, Veves A, editors. Diabetes and cardiovascular disease. Totowa, NJ: Humana Press; 2001. p. 247-79.

17. Simsek C, Magro M, Boersma E, Onuma Y, Nauta ST, Gaspersz MP, et al. The unrestricted use of sirolimus- and paclitaxeleluting stents results in better clinical outcomes during 6-year follow-up than bare-metal stents: an analysis of the RESEARCH (Rapamycin-Eluting Stent Evaluated At Rotterdam Cardiology Hospital) and T-SEARCH (Taxus-Stent Evaluated At Rotterdam Cardiology Hospital) registries. JACC Cardiovasc Interv. 2010;3(10):1051-8. 